\title{
Multidrug Resistance and Serotype Distribution of Salmonella Enterica Isolated from Homemade Recipe Fermented Ground Pork (Nham) in Northeastern Thailand
}

\author{
Thi-Hoang-Nga Vo ${ }^{1}$, Kochakorn Direksin ${ }^{1, *}$, Nawarat Rattanadilok-Na-Phuket ${ }^{2}$, \\ Thitima Nutravong ${ }^{3}$ and Anusak Kerdsin ${ }^{4}$
}

${ }^{I}$ Division of Livestock Medicine, Faculty of Veterinary Medicine, Khon Kaen University, Khon Kaen 40002, Thailand

${ }^{2}$ Department of Microbiology, Regional Medical Sciences Center 7, Khon Kaen Province, Ministry of Public Health, Khon Kaen 40000, Thailand

${ }^{3}$ Department of Microbiology, Faculty of Medicine, Khon Kaen University, Khon Kaen 40002, Thailand

${ }^{4}$ Department of Community Health, Faculty of Public Health, Kasetsart University,

Chalermphrakiat Sakon Nakhon Province Campus, Sakon Nakhon 47000, Thailand

("Corresponding author’s e-mail: kochakrn@kku.ac.th)

Received: 19 August 2020, Revised: 19 March 2021, Accepted: 19 April 2021

\begin{abstract}
Salmonellosis is caused by a thousand serotypes of Salmonella enterica. The sour taste inherent to Nham leads people believe that this fermented ground pork dish is safe from pathogenic microorganisms. The aim of this study was to evaluate the prevalence, serotype, drug susceptibility, and antimicrobial resistance (AMR) genes of Salmonella spp. in homemade recipes of Nham. There were 52 samples from different Nham makers in 3 northeastern provinces of Thailand collected between August and November 2019. Further, 30 Salmonella isolates (57.7 \%) and 14 different serovars were identified: $S$. Rissen (23.3 $\%)$ was the most prevalent, followed by $S$. Typhimurium (16.7 \%), $S$. Give and $S$. Virchow (10 \% each), and $S$. Agona and $S$. Kouka (6.7 \% each). All isolates carried AMR genes but 7 (23.3\%) were antibiotic susceptible and $23(76.7 \%)$ borne a resistance phenotype. The Salmonella isolates were resistant to tetracycline (63\%), sulfamethoxazole/trimethoprim (36.7\%), streptomycin (33.3\%), nalidixic acid (30 $\%$ ), cefotaxime (16.7\%), and enrofloxacin (3.3\%). Among the 23 AMR genes in our analysis, there were gyrB (100 \%), tetA (93.3\%), aadA (93.3\%), sul1, sul2, sul3 (23.3 - $33.3 \%)$, dfrA12 (16.7\%), qnrS, (6.7 $\%)$, and mcr6 $(6.7 \%)$. Two strains had the mcr6 gene but were susceptible to colistin. Our findings suggest that naturally occurring lactic acid bacteria in the Nham products are insufficient to inhibit Salmonella contamination of this pork-based food.
\end{abstract}

Keywords: Antimicrobial resistance, Gene, Nham, Pork, Salmonella

\section{Introduction}

Salmonellosis is considered as a zoonotic disease and the route of infection is often linked to pork consumption [1]. While systematic public health monitoring is on-going, a local survey is necessary to assess specific factors and the risks of infection in the food chain. In Thailand, the prevalence of pigs carrying Salmonella has been reported to be around $35 \%$ [2], but Salmonella contamination rates in pork were 82 - 86 $\%[3,4]$. This huge detection gap is probably due to cross-carcass contamination during cutting at lairages or handling at retail markets. A homemade recipe for fermented ground pork (Nham) consists of minced pork meat mixed with thinly sliced boiled pig skin, garlic, salt, sugar, cooked rice, and incubated at room temperature for natural acidic fermentation. Nham is a traditional food and is preferentially consumed raw in the northern and northeastern regions of Thailand. Its sour taste leads people to believe that Nham is safe from pathogenic microorganisms [5]. However, this belief cannot be guaranteed as seen by the high incidences of Salmonella food poisoning in northeastern Thailand. Homemade Nham recipes vary in their ingredients, which natural lactic acid-producing bacteria are used for the fermentation, and the critical temperatures used in each step. To ensure safety of this product, it is necessary to survey the quality regularly. The aim of this study was to investigate the prevalence, serotypes, antimicrobial susceptibility, and the antimicrobial resistance genes 
present in the Salmonella spp. isolated from homemade Nham prepared in 3 northeastern provinces of Thailand.

\section{Materials and methods}

\section{Sample size calculation}

Sample size was calculated by using the "Estimate Percentage" function [6]. Considering " $85 \%$ " to be the approximate rate of Salmonella contamination in pork samples in Thailand [4], this value was used as the expected prevalence. The "e" and "Z1- $\alpha / 2$ " values were selected as $10 \%$ and 0.95 , respectively, as the necessary feature parameters. A sample size of at least 49 was indicated.

\section{Sample collection}

Homemade Nham samples were randomly collected at local retail shops representing 52 different Nham makers in the Khon Kaen $(n=20)$, Kalasin $(n=16)$, and Roi-Ed $(n=16)$ provinces between August and November 2019. The venders' consents did not include the disclosure of their names. All samples were kept in a sterile plastic bag individually, then transported to the laboratory within $10 \mathrm{~h}$. The Salmonella culturing was performed at the Veterinary Diagnostic Laboratory of Research, Faculty of Veterinary Medicine, Khon Kaen University, Thailand.

\section{Salmonella isolation and identification}

For each brand, 3 to 5 pieces per batch of Nham were removed and each corresponding package was opened to check for $\mathrm{pH}$ of below 5 before bacterial culturing took place. If the $\mathrm{pH}$ was not yet less than 5 , then the other pieces were allowed to ferment until they reached this acidic $\mathrm{pH}$. The $\mathrm{pH}$ value of Nham was determined by homogenizing $10 \mathrm{~g}$ of Nham in $100 \mathrm{~mL}$ of sterile distilled water and then using a $\mathrm{pH}$ meter (Merk, Coulter). The isolation of Salmonella spp. was performed according to standard methods (ISO 6579:2002/Amendment 1:2017, Annex D). In brief, $25 \mathrm{~g}$ of Nham was added into $225 \mathrm{~mL}$ of Buffered Peptone Water (BPW, Oxoid, United Kingdom), mixed, and incubated at $37{ }^{\circ} \mathrm{C}$ for $18-24 \mathrm{~h}$. The inoculated BPW was then transferred to Modified Semi-Solid Rappaport Vassiliadis (MSRV) medium (Oxoid, United Kingdom) using 3 loops; each loop was inoculated at the peripheral area on the MSRV plate and then incubated at $42{ }^{\circ} \mathrm{C}$ for $18-24 \mathrm{~h}$. Positive colonies in the MSRV media were transferred to xylose lysine deoxycholate agar (XLD, Oxoid, United Kingdom), and then incubated at $37{ }^{\circ} \mathrm{C}$ for $18-24 \mathrm{~h}$. Three Salmonella-positive colonies were chosen to be transferred into triple sugar iron agar (TSI, Oxoid, United Kingdom) and motility indole lysine medium (MIL, Himedia, India) then incubated at $37{ }^{\circ} \mathrm{C}$ for $18-24 \mathrm{~h}$. Only typical Salmonella biochemistry in the TSI and MIL tests were selected for further grouping and serotyping.

\section{Salmonella grouping and serotyping}

A Kauffman-White classification scheme was used for grouping and serotyping the Salmonella isolates [7]. All Salmonella isolates were serotyped at the Regional Medical Sciences Center 7, Ministry of Public Health, Khon Kaen province, Thailand. The slide agglutination test against $\mathrm{O}$ and $\mathrm{H}$ antigens utilizing commercial antisera (S \& A. Reagent Laboratory LMT, Bangkok, Thailand) was used to group the Salmonella isolates following the manufacturing's instruction.

\section{Antimicrobial susceptibility testing}

The disc diffusion method was employed, and this procedure was in compliance with the Clinical and Laboratory Standards Institute (CLSI) [8]. Seven antimicrobial agents were used for susceptibility, including cefotaxime $30 \mu \mathrm{g}$ (CTX), nalidixic acid $30 \mu \mathrm{g}$ (NAL), enrofloxacin $5 \mu \mathrm{g}$ (ENR), streptomycin $10 \mu \mathrm{g}$ (STR), sulfamethoxazole/trimethoprim $25 \mu \mathrm{g}$ (SXT), and tetracycline $30 \mu \mathrm{g}$ (TET) (Oxoid, United Kingdom). The minimum inhibitory concentration (MIC) and the micro-broth dilution method were used to determine colistin susceptibility [9]. The standard Escherichia coli ATCC® 25922 was included as a quality control. The result of the antimicrobial resistance was determined by the diameter of the inhibition zone and the MIC breakpoints according to CLSI [8] and EUCAST [10].

\section{Identification of antimicrobial resistance genes}

Chromosomal DNA was extracted using the GF-1 nucleic acid extraction kit (Vivantis, Selangor Darul Ehsan, Malaysia). PCR primers used in this study are listed in Table 1. All PCR amplifications were performed using 2X Vired PCR Master Mix (Vivantis, Selangor Darul Ehsan, Malaysia). The PCRs were performed in a $20 \mu \mathrm{L}$ volume containing $10 \mathrm{ng}$ DNA, $0.5 \mu \mathrm{M}$ each of forward and reverse primers, and $10 \mu \mathrm{L} 2 \mathrm{X}$ Vired Taq Master Mix (Vivantis, Selangor Darul Ehsan, Malaysia). For nucleotide sequencing analysis, PCR amplicons were purified using the GF-1 AmbiClean kit gel and PCR (Vivantis; Selangor Darul Ehsan) and then submitted for further analysis at the First Base Company, Malaysia. The 
DNA sequences obtained were compared to the Genbank database using the blast algorithm available on the National Center for Biotechnology Information website [11].

All nalidixic acid-resistant Salmonella strains were further examined for mutations in the quinolone resistance determinant region (QRDR) of gyrB and parC [12] using PCR and DNA sequencing. The gyrB and $\operatorname{par} C$ of 2 standard nalidixic acid-susceptible strains were included as negative controls. The presence of plasmid-mediated quinolone resistance (PMQR) on the $q n r A, q n r B$, and $q n r S$ genes was determined in all Salmonella isolates as described previously [13]. The E. coli qnr-positive strains served as positive controls [14]. Multiplex PCR was employed to screen 8 colistin resistance genes (mcr 1-8), then confirmed the positive samples by single PCR under the same condition [15-17].

Table 1 Antimicrobial resistance genes, primer sequences, amplicon sizes, and annealing temperatures utilized in our study.

\begin{tabular}{|c|c|c|c|c|c|c|}
\hline No. & Gene & Primer & $\begin{array}{c}\text { Primer sequences } \\
\end{array}$ & $\operatorname{Tm}\left({ }^{\circ} \mathrm{C}\right)$ & Size (bp) & Reference \\
\hline 1 & tetA & $\begin{array}{l}\text { tetA F } \\
\text { tetA R }\end{array}$ & $\begin{array}{l}\text { GCTACATCCTGCTTGCCTTC } \\
\text { CATAGATCGCCGTGAAGAGG }\end{array}$ & 50 & 210 & {$[18]$} \\
\hline 2 & tetB & $\begin{array}{l}\text { tetB F } \\
\text { tetB R }\end{array}$ & $\begin{array}{l}\text { CAGTGCTGTTGTTGTCATTAA } \\
\text { GCTTGGAATACTGAGTGTAA }\end{array}$ & 50 & 571 & {$[12]$} \\
\hline 3 & tet $C$ & $\begin{array}{l}\text { tetC F } \\
\text { tetC R }\end{array}$ & $\begin{array}{l}\text { CTTGAGAGCCTTCAACCCAG } \\
\text { ATGGTCGTCATCTACCTGCC }\end{array}$ & 55 & 418 & {$[19]$} \\
\hline 4 & $q n r A$ & $\begin{array}{l}\text { qnrA F } \\
\text { qnrA R }\end{array}$ & $\begin{array}{l}\text { ATTTCTCACGCCAGGATTTG } \\
\text { GATCGGCAAAGGTTAGGTCA }\end{array}$ & 55 & 516 & {$[20]$} \\
\hline 5 & $q n r B$ & $\begin{array}{l}\text { qnrB F } \\
\text { qnrB R }\end{array}$ & $\begin{array}{l}\text { TCGGCTGTCAGTTCTATGATCG } \\
\text { TCCATGAGCAACGATGCCT }\end{array}$ & 57 & 496 & {$[13]$} \\
\hline 6 & $q n r S$ & $\begin{array}{l}\text { qnrS-F } \\
\text { qnrS-R }\end{array}$ & $\begin{array}{l}\text { TGATCTCACCTTCACCGCTTG } \\
\text { GAATCAGTTCTTGCTGCCAGG }\end{array}$ & 58 & 566 & {$[13]$} \\
\hline 7 & $d f r A 12$ & $\begin{array}{l}\text { dfrA12-F } \\
\text { dfrA12-R }\end{array}$ & $\begin{array}{l}\text { TTAGCCGTTTCGACGCGCAT } \\
\text { ATGAACTCGGAATCAGTACGC }\end{array}$ & 55 & 498 & {$[21]$} \\
\hline 8 & $\operatorname{aad} A$ & $\begin{array}{l}\text { aadA F } \\
\text { aadA R }\end{array}$ & $\begin{array}{l}\text { TGATTTGCTGGTTACGGTGAC } \\
\text { CGCTATGTTCTCTTGCTTTTG }\end{array}$ & 56 & 284 & {$[22]$} \\
\hline 9 & sull & $\begin{array}{l}\text { sul1-F } \\
\text { sul1-R }\end{array}$ & $\begin{array}{l}\text { TGGTGACGGTGTTCGGCATTC } \\
\text { GCGAGGGTTTCCGAGAAGGTG }\end{array}$ & 55 & 790 & {$[12]$} \\
\hline 10 & sul2 & $\begin{array}{l}\text { sul2-F } \\
\text { sul2-R }\end{array}$ & $\begin{array}{l}\text { CCTGTTTCGTCCGACACAGA } \\
\text { GAAGCGCAGCCGCAATTCAT }\end{array}$ & 53 & 435 & {$[12]$} \\
\hline 11 & sul3 & $\begin{array}{l}\text { sul3-F } \\
\text { sul3-R }\end{array}$ & $\begin{array}{l}\text { ATGAGCAAGATTTTTGGAATCGTA } \\
\text { A CTAACCTAGGGCTTTGGATATTT }\end{array}$ & 53 & 792 & [12] \\
\hline 14 & gyrB & $\begin{array}{l}\text { gyrB F } \\
\text { gyrB R }\end{array}$ & $\begin{array}{l}\text { CTGCGCTATCACAGCATCAT } \\
\text { CGCGATGGAAATCTGGTACT }\end{array}$ & 56 & 219 & [12] \\
\hline 15 & $\operatorname{par} C$ & $\begin{array}{l}\operatorname{parC} F \\
\operatorname{parC~R}\end{array}$ & $\begin{array}{l}\text { CTATGCGATGTCAGAGCTGG } \\
\text { TAACAGCAGCTCGGCGTATT }\end{array}$ & 59 & 262 & [23] \\
\hline 16 & mcrl & $\begin{array}{l}\operatorname{mor} 1 F \\
\operatorname{mer} 1 \mathrm{R}\end{array}$ & $\begin{array}{l}\text { TTGCAAATTCACGCCAGTG } \\
\text { CTTTGACTTTGTCCGCGGTG }\end{array}$ & 62 & 383 & [17] \\
\hline 17 & $m c r 2$ & $\begin{array}{l}\operatorname{mcr} 2 \mathrm{~F} \\
\mathrm{mcr} 2 \mathrm{R}\end{array}$ & $\begin{array}{l}\text { CAAGTGTGTTGGTCGCAGTT } \\
\text { TCTAGCCCGACAAGCATACC }\end{array}$ & 62 & 715 & \\
\hline 18 & $m c r 3$ & $\begin{array}{l}\operatorname{mcr} 3 \mathrm{~F} \\
\mathrm{mcr} 3 \mathrm{R}\end{array}$ & $\begin{array}{l}\text { CTGAACTGGCGTGGAGTTCT } \\
\text { ATCATCCGGTGCAAACTGGT }\end{array}$ & 62 & 1350 & \\
\hline 19 & $m c r 4$ & $\begin{array}{l}\operatorname{mcr} 4 \mathrm{~F} \\
\operatorname{mcr} 4 \mathrm{R}\end{array}$ & $\begin{array}{l}\text { TCACTTTCATCACTGCGTTG } \\
\text { TTGGTCCATGACTACCAATG }\end{array}$ & 62 & 1116 & $\begin{array}{l}{[16]} \\
{[15]}\end{array}$ \\
\hline 20 & $m c r 5$ & $\begin{array}{l}\operatorname{mcr} 5 \mathrm{~F} \\
\operatorname{mcr} 5 \mathrm{R}\end{array}$ & $\begin{array}{l}\text { ATGCGGTTGTCTGCATTTATC } \\
\text { TCATTGTGGTTGTCCTTTTCTG }\end{array}$ & 62 & 1641 & \\
\hline 21 & mcr6 & $\begin{array}{l}\text { mcr6 F } \\
\text { mcr6 R }\end{array}$ & $\begin{array}{l}\text { GTCCGGTCAATCCCTATCTGT } \\
\text { ATCACGGGATTGACATAGCTAC }\end{array}$ & 62 & 1022 & \\
\hline 22 & $m c r 7$ & $\begin{array}{l}\operatorname{mcr} 7 \mathrm{~F} \\
\operatorname{mcr} 7 \mathrm{R}\end{array}$ & $\begin{array}{l}\text { TGCTCAAGCCCTTCTTTTCGT } \\
\text { TTCATCTGCGCCACCTCGT }\end{array}$ & 62 & 892 & \\
\hline 23 & mcr8 & $\begin{array}{l}\text { mcr8 F } \\
\text { mcr8 R }\end{array}$ & $\begin{array}{l}\text { GCGGGTAACCAACCCCTATC } \\
\text { TGCCGGCATATCATCTGTGG }\end{array}$ & 62 & 265 & \\
\hline
\end{tabular}

Legend: F-Forward, R-Reverse 


\section{Results}

The Nham samples had an average $\mathrm{pH}$ of $4.25 \pm 0.25$ (median value of 4.21 ; lowest 3.68 to highest 4.97). A total of 30 Salmonella isolates were detected from 52 samples. The overall prevalence of Salmonella in Nham was $57.7 \%$. Nham collected from the Khon Kaen $(60 \%, 12 / 20)$, Kalasin $(62.5 \%$, 10/16), and Roi Et $(50 \%, 8 / 16)$ provinces were Salmonella-isolate positive. There were 14 different serovars of Salmonella identified in this study. The Salmonella serovars identified in Nham in descending frequency were $S$. Rissen $(23.3 \%, 7 / 30), S$. Typhimurium $(16.7 \%, 5 / 30), S$. Give, and $S$. Virchow (10\%, $3 / 30$ each), $S$. Agona, and $S$. Kouka (6.7\%, 2/30 each). There was one isolate in each of the following serovars found in each Nham sample, $S$. Brandenburg, $S$. Derby, $S$. Hvittingfoss, $S$. Idiken, $S$. London, $S$. Paratyphi B, S. Senftenberg, and $S$. Regent (3.3\%, 1/30 each) (Figure 1).

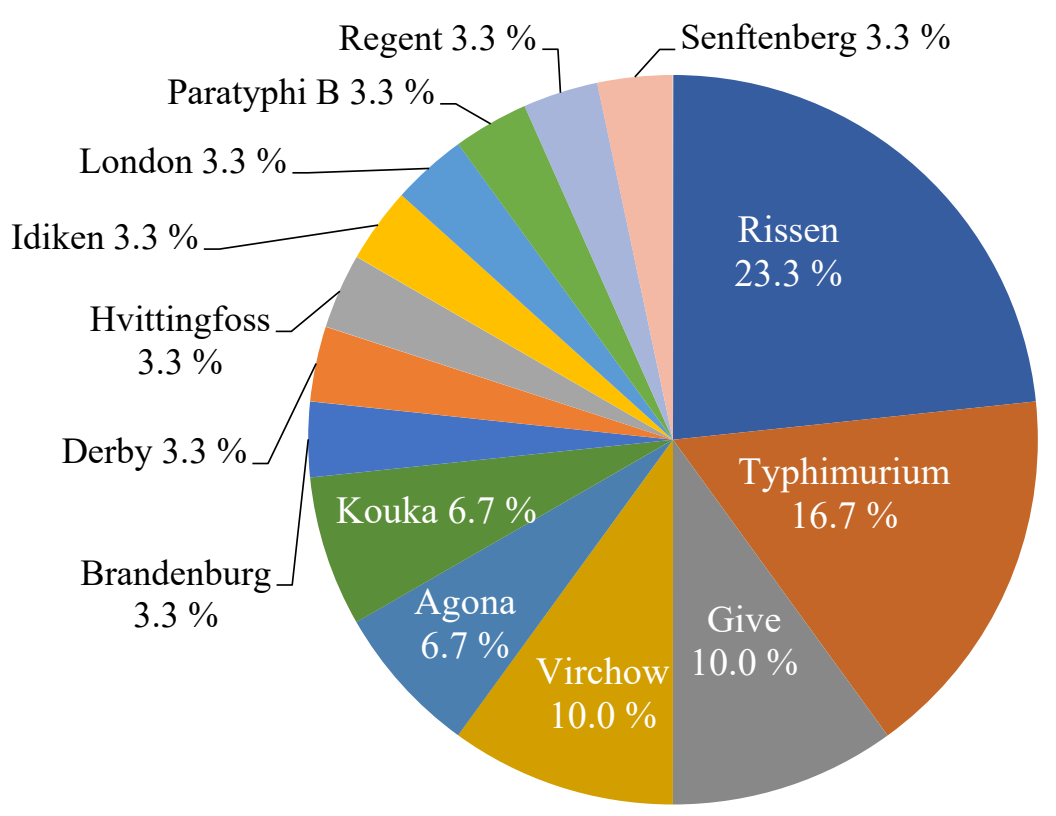

Figure 1 Serotypes of Salmonella isolated from Nham collected from the Khon Kaen, Kalasin, and Roi Et provinces, northeastern Thailand $(\mathrm{n}=30)$.

Salmonella isolates were resistant to tetracycline $(63.3 \%)$, sulfamethoxazole/trimethoprim $(63.7$ $\%$ ), streptomycin (33.3\%), nalidixic acid (30\%), cefotaxime (16.7\%), and enrofloxacin (3.3\%). In contrast, all 30 isolates were susceptible to colistin (Figure 2). Among the 30 Salmonella isolates, 7 (23.3 $\%)$ were antibiotic susceptible, whereas $23(76.7 \%)$ were resistant to antibiotics. Of these resistant isolates, 6 isolates resisted one drug, another 7 isolates were resistant to 2 classes of antibiotics, and the last 10 isolates borne multiple drug resistance (MDR) (Table 2). There was only one isolate belonging to serovar $S$. Kouka that resisted enrofloxacin $(3.3 \%)$ and 5 isolates that were cefotaxime resistant $(16.7 \%)$ (Table 2). The multidrug-resistant isolates, which resisted at least 3 drugs, belonged to serovars $S$. Agona, $S$. Give, $S$. Hvittingfoss, $S$. Kouka, $S$. London, $S$. Regent, $S$. Rissen, and $S$. Typhimurium (Table 2).

Conventional PCR was used to analyze the 23 AMR genes associated with colistin, quinolone, streptomycin, tetracycline, sulfamethoxazole, trimethoprim, and colistin antibiotics. Table 2 presents detailed results of the AMR genes carried by each isolate. The highest prevalence of AMR genes was gyrB $(100.0 \%)$ followed by tetA and aadA (93.3\%). All of the sulfonamide resistance genes (sul1, sul2, sul3) were detected with 23.3 to $30.0 \%$ prevalence, but the trimethoprim resistance gene, $d f r A 12$, was found to have only $16.67 \%$ prevalence. Only one plasmid-mediated quinolone resistance gene, qnrS, was found (6.7 $\%$ ) in the isolates examined, which was detected in $S$. Typhimurium. One colistin resistance gene, $m c r 6$, was detected $(6.7 \%)$ in our analysis (Figure 3), as well. Serotypes carrying mcr6 were $S$. Brandenburg and $S$. Rissen (Table 2). 


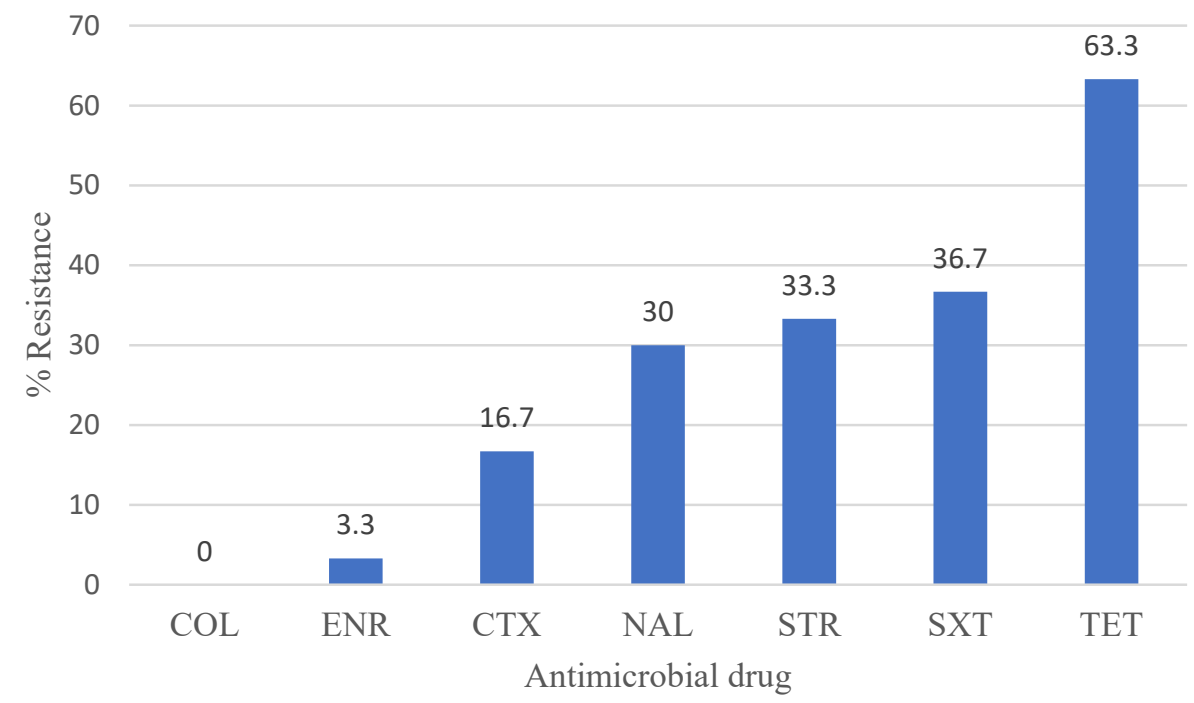

Figure 2 The proportion of the 30 antimicrobial-resistant Salmonella isolates against the 7 classes of antimicrobial drugs.

Legend: CTX-cefotaxime, NAL-nalidixic acid, ENR-enrofloxacin, STR-streptomycin, SXTsulfamethoxazole/ trimethoprim, TET-tetracycline, COL-colistin (for this drug, determined by MIC)

Table 2 Antimicrobial resistant patterns and AMR gene profiles of the 30 Salmonella isolates.

\begin{tabular}{|c|c|c|c|}
\hline $\begin{array}{c}\text { No. } \\
\text { sample }\end{array}$ & Serovar & $\begin{array}{c}\text { Resistant pattern } \\
\text { (MIC and/or agar disc diffusion) }\end{array}$ & Resistance gene \\
\hline 1. NH-7 & Agona & susceptible & tet $A, \operatorname{aad} A$, gyrB ${ }^{a}$ \\
\hline 2. $\mathrm{NH}-21$ & Agona & STR- SXT- TET & tetA, aadA, sul3, gyrB $B^{a}$ \\
\hline 3. NH-15 & Brandenburg & susceptible & tet $A$, tetB, sull, aadA, gyrB ${ }^{a}, \operatorname{par}^{d}$, mer6 \\
\hline 4. NH-2 & Derby & SXT- TET & tetA, dfrA12, aadA, sul1, sul3, gyrB $B^{a}, \operatorname{par}^{b}$ \\
\hline 5. NH-28 & Give & CTX-NAL-STR-SXT-TET & tet $A, d f r A 12$, addA, sul1, gyr $B^{a}$ \\
\hline 6. NH-31 & Give & NAL & tet $A$, add $A$, gyr $B^{b}$ \\
\hline 7. NH-35 & Give & NAL & tetA, $\operatorname{gyr} B^{a}, \operatorname{parC}^{d, e, f}$ \\
\hline 8. NH-9 & Hvittingfoss & NAL- STR- SXT & tetA, aadA, sull, gyrB ${ }^{a}, \operatorname{par}^{b}$ \\
\hline 9. NH-10 & Idiken & SXT-TET & tetA, sul3, aadA, gyrB ${ }^{a}, \operatorname{par}^{d}$ \\
\hline 10. NH-24 & Kouka & STR- TET & tetA, aadA, sul3, gyrB $B^{a}, \operatorname{parC}^{d, e, f}$ \\
\hline 11. NH-27 & Kouka & CTX-ENR-NAL-STR-SXT & tetA, addA, sul2, gyr $B^{a}$ \\
\hline 12. NH-22 & London & CTX-SXT- TET & tet $A, \operatorname{add} A, \operatorname{gyr} B^{a}$ \\
\hline 13. NH-32 & Paratyphi B & susceptible & tet $A$, add $A, \operatorname{gyr} B^{a}$ \\
\hline 14. NH-33 & Regent & NAL- SXT- TET & tetA, dfrA12, addA, sul3, qurS, gyrB $B^{b}, \operatorname{par} C^{b}$ \\
\hline 15. NH-12 & Rissen & TET & tetA, sul3, aadA, gyrB ${ }^{a}, \operatorname{par}^{e}$ \\
\hline 16. NH-13 & Rissen & STR- SXT- TET & tetA, tetB, sull, sul2, aad $, \operatorname{gyr} B^{a}, \operatorname{par}^{b}$ \\
\hline 17. NH-19 & Rissen & STR- TET & tet $A$, tet $B$, aad $A$, sull, gyr $B^{a}$, mcr6 \\
\hline 18. NH-20 & Rissen & susceptible & tetA, sul1, sul3, aadA, gyrB $B^{a}, \operatorname{par}^{d}$ \\
\hline 19. NH-26 & Rissen & CTX- NAL- STR-TET & tetA, addA, sul2, gyrB ${ }^{b}$ \\
\hline 20. NH-29 & Rissen & susceptible & tetA, addA, sul3, gyrB ${ }^{a}, \operatorname{par}^{d}$ \\
\hline 21. NH-34 & Rissen & TET & tet $A, \operatorname{gyr} B^{a}$ \\
\hline 22. NH-3 & Senftenberg & SXT- TET & tetA, dfrA12, aadA, sul1, sul2, sul3, gyrB ${ }^{a}, \operatorname{par} C^{e}$ \\
\hline
\end{tabular}




\begin{tabular}{|c|c|c|c|}
\hline $\begin{array}{c}\text { No. } \\
\text { sample }\end{array}$ & Serovar & $\begin{array}{c}\text { Resistant pattern } \\
\text { (MIC and/or agar disc diffusion) }\end{array}$ & Resistance gene \\
\hline 23. NH-4 & Typhimurium & STR- TET & tetA, tetB, sul2, sul3, aadA, gyr $B^{a}$ \\
\hline 24. NH-17 & Typhimurium & STR- TET & tet $A$, tet $B$, aad $A, \operatorname{gyr} B^{a}$ \\
\hline 25. NH-23 & Typhimurium & TET & $\operatorname{tet} A, \operatorname{tet} B, \operatorname{aad} A, \operatorname{gyr} B^{a, b, c}$ \\
\hline 26. NH-25 & Typhimurium & NAL- STR- TET & tetA, tetB, addA, sull, sul2, gyr $B^{a, b, c}$ \\
\hline 27. NH-30 & Typhimurium & NAL-SXT-TET & $\begin{array}{l}\operatorname{tet} A, \operatorname{dfr} A 12, \text { addA, sul2, sul3, qnrS, gyrB }{ }^{b} \text {, } \\
\operatorname{parC} C^{d, e, f}\end{array}$ \\
\hline 28. NH-1 & Virchow & susceptible & aadA, $\operatorname{gyr} B^{a}$ \\
\hline 29. NH-5 & Virchow & susceptible & tet $A$, aad $A$, gyr $B^{a}$ \\
\hline 30. NH-6 & Virchow & CTX & $\operatorname{aad} A, \operatorname{gyr} B^{b}$ \\
\hline
\end{tabular}

Legend: CTX-cefotaxime, NAL-nalidixic acid, ENR-enrofloxacin, STR-streptomycin, SXT-sulfamethoxazole/ trimethoprim, TET-tetracycline

${ }^{\mathrm{a}}$ GyrB mutation point: G-144 $\rightarrow \mathrm{T},{ }^{\mathrm{b}}$ GyrB mutation point: C-133 $\rightarrow \mathrm{T}$, ${ }^{\mathrm{c}}$ GyrB mutation point: $\mathrm{G}-144 \rightarrow \mathrm{T}$ and C-133 $\rightarrow \mathrm{T}$

${ }^{\mathrm{d}}$ ParC mutation point: $\mathrm{C}-92 \rightarrow \mathrm{T}$; ${ }^{\mathrm{e}}$ ParC mutation point: $\mathrm{T}-230 \rightarrow \mathrm{G}$, ${ }^{\mathrm{f}} \operatorname{ParC}$ mutation point: $\mathrm{C}-92 \rightarrow \mathrm{T}$ and $\mathrm{T}-230 \rightarrow \mathrm{G}$

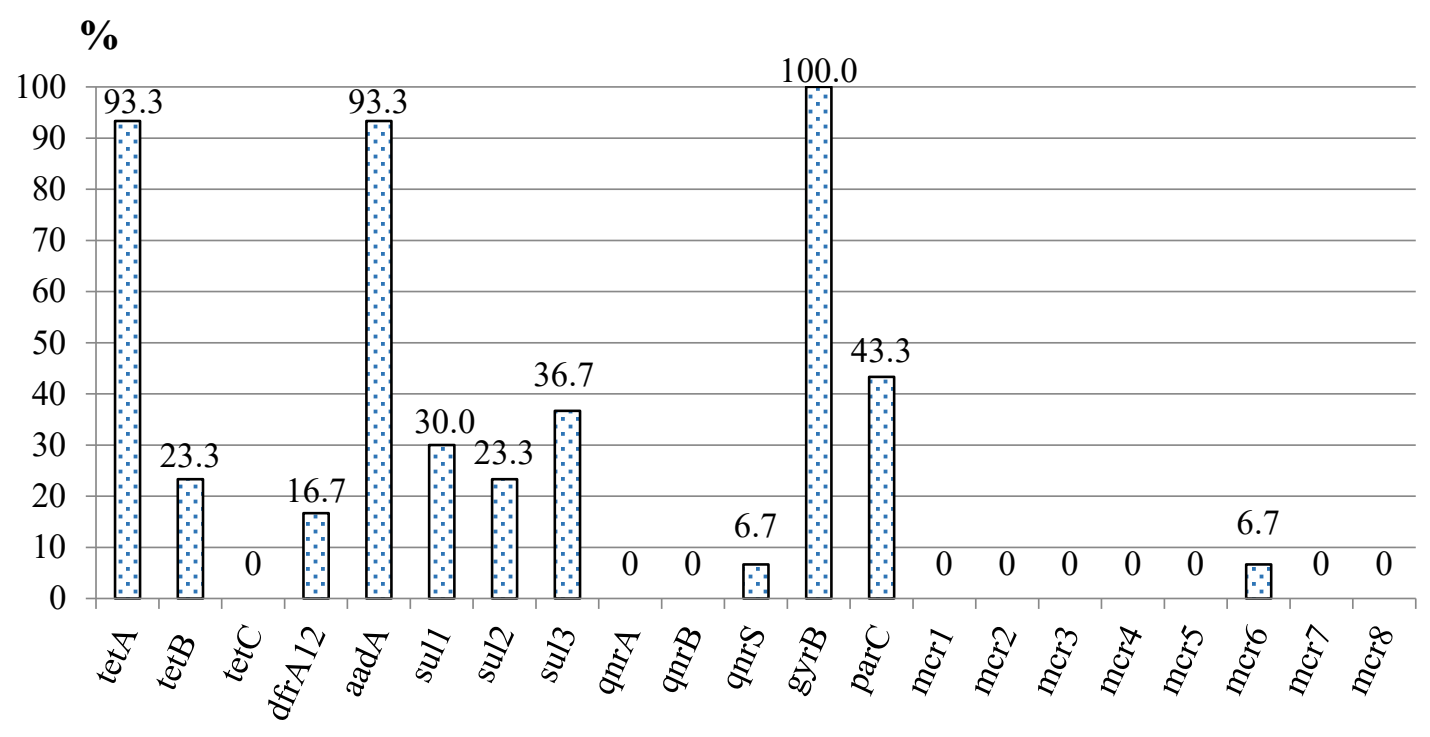

Figure 3 Proportion of the AMR genes found in the 30 Salmonella isolates.

\section{Discussion}

Salmonella can be detected at any level along the food preparation chain, including farm, transportation, carcass handling, and food preparation [24]. Environment and equipment, such as the floor, surfaces, knives, cutting boards, and storage places, were possible sources of Salmonella contamination. Therefore, strict hygiene is mandated in food production processes. The main ingredients in Nham are composited ground pork and pig skin derived from many carcasses combined all together and processed by various handlers. According to previous research, the rate of Salmonella in minced pork and pig skin could be as high as $100 \%$ [25]. Homemade Nham recipes use ingredients and create an environment for natural lactic acid-producing bacteria. Fermentation reduces the $\mathrm{pH}$, and hence excludes other pathogens [5]. However, Salmonella spp. can grow in a pH range of 5 - 9 [26] but with only limited growth below pH 4.5 [27]. Thai industrial standard 1219 - 2547 (2004) stipulates that a food $\mathrm{pH}$ of below 4.6 is safe for consuming fermented products raw. However, the $\mathrm{pH}$ of Nham samples in our study ranged from 3.68 - 4.97; this low $\mathrm{pH}$ range did not seem to eliminate the Salmonella from the products. In addition to the selection of clean and safe ingredients, many crucial factors during fermentation, such as temperature or delayed growth of lactic acid-producing bacteria, may allow Salmonella to thrive [28]. Unlike homemade products, commercial fermented foods use start culture or standard lactic acid bacteria, such as Lactobacillus spp., Pediococcus spp., Streptococcus spp., and yeast, that grow rapidly and outcompete a number of other pathogens [29]. 
Salmonella can disseminate into humans via the food chain. In Thailand, $S$. Rissen and $S$. Typhimurium were the most prevalent serovars in pork and ready-to-eat products [30]. Similarly, the top2 most prevalent Salmonella serotypes discovered from Nham in our study were $S$. Rissen and $S$. Typhimurium. These serotypes were also predominantly found in butcher and pork vendor patients in Lao PDR and Thailand [31]. In addition, $S$. Rissen was frequently detected both in healthy and diarrheal pigs in South Korea [32], and this serovar was mostly encountered in retail pork in Vietnam [33]. In Thailand, $S$. Rissen has been long reported to be one of the most frequent serotypes identified in swine herds [2,34]. In addition, $S$. Rissen has been shown to be efficiently transmitted from swine to humans involved in pork processing [30]. Although $S$. Weltevreden was a common serotype found in human stool, food, and animals in South and Southeast Asia [35], this serotype was not detected in our study.

More than $70 \%$ of Salmonella isolates in our study were resistant to antibiotics. Multidrug-resistant Salmonella was identified at a relatively high rate with 3 to 5 drug class-resistant patterns. Our results indicate that Salmonellae were most resistant to tetracycline, sulfamethoxazole/trimethoprim, and streptomycin. Multidrug-resistant Salmonella has been considered widespread in farm environments [36]. This AMR pattern was in accordance with in-feed and injectable medications commonly used in pig farms in Thailand. This current result was similar to previous studies conducted in Thailand, Vietnam, and South Korea [31-33]. Cephalosporins and quinolones are the first-choice medication for Salmonellosis therapy in human, and colistin is the drug of last resort in treatment [37]. Especially, colistin has been increasingly used as one of the alternative options for treating carbapenem-resistant Enterobacteriaceae in humans. Nationwide campaigns dictate the precautious use of these critical agents in livestock; however, this policy seems to be limited to AMR Salmonella of swine origin. From 30 Salmonella isolates, there was only one isolate resistant to enrofloxacin and 5 isolates resistant to cefotaxime. However, the AMR genes correspondent to cephalosporins were not included in our analyses. Enrofloxacin is a quinolone registered for use only in animals. Precautious use of this medicine is strongly recommended since the development of bacterial resistance to this drug might parallel that of other fluoroquinolone drugs. All isolates in our study were susceptible to colistin. This was probably why colistin has not been advised to be used in livestock in Thailand for a few years.

A total of 23 AMR genes were determined in 30 isolates corresponding to colistin, quinolone, streptomycin, tetracycline, sulfamethoxazole, trimethoprim, and colistin resistance. The most prevalentlydetected genes were gyrB (100\%), tetA (93.3\%), and aadA (93.3\%). Secondly, sulfonamide resistance genes (sul1, sul2, sul3) were identified. Trimethoprim resistance gene, $d f r A 12$, presented as the third-most frequent. Whereas the quinolone-resistant $q n r S$ and the colistin-resistant $m c r 6$ genes were the least detected, only quinolone resistance in the determinant region of Enterobacteriaceae is associated with a point mutation in gyrA, gyrB and $\operatorname{parC}$ [37]. However, quinolone resistance in Salmonella can be mediated by other genes associated to its plasmid that were not evaluated in this study. Plasmid-mediated colistin resistance conferred by the $m c r 1, m c r 2, m c r 3, m c r 4$, and $m c r 5$ genes have already been identified in several serovars of Salmonella enterica [38]. We did not find a colistin-resistant phenotype but detected 2 isolates harboring the mcr6 gene. Generally, the prevalence of colistin resistance in Salmonella isolated from healthy animals is low [39]. In addition, there were 7 Salmonella isolates carrying AMR genes but susceptible to the correspondent antibiotics. The discrepancy between genotype and phenotype can be explained by a lack of gene expression, ancestral genes that require mutation, or other genes required in parallel to confer resistance traits. Otherwise, bacteria may resist medication by physical or chemical adaptation without any change in their genotypes.

\section{Conclusions}

There is an urgent need for Hazard Analysis Critical Control Point (HACCP) in meat processing and homemade Nham production processes due to a relatively high Salmonella prevalence and antibiotic resistance found in the product. Such steps to mitigate Salmonella infections include selecting Salmonella-free pork, finding an appropriate storage place and temperature, applying good hygiene, using standard fermentation cultures, and evaluating product safety. Another alternative method for pathogen elimination in pork is radiating, freezing and then thawing the meat before producing Nham. An investigation into the food supply chain contaminated with MDR Salmonella and the interplay between animal hosts, food, and environment should be undertaken. Governmental strengthening of the surveillance system to control and prevent the dissemination of MDR Salmonella between animals or animal products to humans is indicated by our data. 


\section{Acknowledgements}

We acknowledge Professor Dr. Toshiyuki Murase, Assistant Professor Dr. Patchara Phuektes, and Miss Sunsanee Supankong for kindly providing reagents and technical advices. This research is financially supported by the Research grant for graduate students of the Faculty of Veterinary Medicine, Khon Kaen University, Thailand (Project No. 605180007-1/2561) and Kasetsart University Research and Development Institute, Kasetsart University, Thailand.

\section{References}

[1] J Campos, J Mourao, L Peixe and P Antunes. Non-typhoidal Salmonella in the pig production chain: a comprehensive analysis of its impact on human health. J. Pathog. 2019; 8, 19.

[2] P Tadee, K Kumpapong, D Sinthuya, P Yamsakul, N Chokesajjawatee, S Nuanualsuwan, S Pornsukarom, BZ Molla, WA Gebreyes and P Patchanee. Distribution, quantitative load and characterization of Salmonella associated with swine farms in upper-northern Thailand. J. Vet. Sci. $2014 ; \mathbf{1 5}, 327-34$.

[3] N Niyomdecha, N Mungkornkaew and W Samosornsuk. Serotypes and antimicrobial resistance of Salmonella enterica isolated from pork, chicken meat and lettuce, Bangkok and central Thailand. Se. Asian J. Trop. Med. 2016; 47, 31-9.

[4] T Prasertsee, N Chokesajjawatee, P Santiyanont, P Chuammitri, M Deeudom, P Tadee and P Patchanee. Quantification and rep-PCR characterization of Salmonella spp. in retail meats and hospital patients in Northern Thailand. Zoonoses Public Health. 2019; 66, 301-9.

[5] AL Holck, L Axelsson, TM Rode, M Hoy, I Mage, O Alvseike, TM L'Abee-Lund, MK Omer, PE Granum and E Heir. Reduction of verotoxigenic Escherichia coli in production of fermented sausages. Meat Sci. 2011, 89, 286-95.

[6] WinEpi: Working IN EPIdemiology, Avaialble at: http://winepi.net/uk/index.htm, accessed May 2019.

[7] S Issenhuth-Jeanjean, P Roggentin, M Mikoleit, M Guibourdenche, ED Pinna, S Nair, PI Fields and FX Weill. Supplement 2008 - 2010 (no. 48) to the White-Kauffmann-Le minor scheme. Res. Microbiol. 2014, 165, 526-30.

[8] CLSI. Performance standards for antimicrobial disk susceptibility tests; CLSI standard Mo2. Clinical and Laboratory Standards Institute, Wayne, Pennsylvania, 2018.

[9] M Hombach, G Bloemberg and E Bo"ttger. Effects of clinical breakpoint changes in CLSI guidelines 2010/2011 and EUCAST guidelines 2011 on antibiotic susceptibility test reporting of Gram-negative bacilli. J. Antimicrob. Chemother. 2012; 67, 622-32.

[10] EUCAST. Recommendations for reference MIC-testing of colistin (polymyxin E). European Committee on Antimicrobial Susceptibilty Testing. 2016.

[11] BLAST: Basic Local Alignment Search Tool, Avaialble at: https://blast.ncbi.nlm.nih.gov/Blast.cgi, accessed January 2020.

[12] MN Nghiem, VT Nguyen, TTH Nguyen, TD Nguyen and TTB Vo. Antimicrobial resistance gene expression associated with multidrug resistant Salmonella spp. isolated from retail meat in Hanoi, Vietnam. Int. Microbiol. 2017; 20, 85-93.

[13] S Stephenson, PD Brown, A Holness and M Wilks. The emergence of qnr-mediated quinolone resistance among Enterobacteriaceae in Jamaica. West Indian Med. J. 2010; 59, 241-4.

[14] JJ Wu, WC Ko, HM Wu and JJ Yan. Prevalence of Qnr determinants among bloodstream isolates of Escherichia coli and Klebsiella pneumoniae in a Taiwanese hospital, 1999 - 2005. J. Antimicrob. Chemother. 2008; 61, 1234-9.

[15] YQ Yang, AY Zhang, SZ Ma, LH Kong, YX Li, JX Liu, MA Davis, XY Guo, BH Liu, CW Lei and HN Wang. Co-occurrence of mcr-1 and ESBL on a single plasmid in Salmonella enterica. J. Antimicrob. Chemother. 2016; 71, 2336-8.

[16] W Wang, Z Baloch, M Zou, Y Dong, Z Peng, Y Hu, J Xu, N Yasmeen, F Li and S Fanning. Complete genomic analysis of a Salmonella enterica serovar typhimurium isolate cultured from ready-to-eat pork in China carrying one large plasmid containing mcr-1. Front. Microbiol. 2018; 9, 616.

[17] AR Rebelo, V Bortolaia, JS Kjeldgaard, SK Pedersen, P Leekitcharoenphon, IM Hansen, B Guerra, B Malorny, M Borowiak, JA Hammerl, A Battisti, A Franco, P Alba, A Perrin-Guyomard, SA Granier, C De Frutos Escobar, S Malhotra-Kumar, L Villa, A Carattoli and RS Hendriksen. Multiplex PCR for detection of plasmid-mediated colistin resistance determinants, mcr-1, mcr-2, mcr-3, mcr-4 and mcr-5 for surveillance purposes. Euro Surveill. 2018; 23, 17-00672. 
[18] B Doublet, R Lailler, D Meunier, A Brisabois, D Boyd, MR Mulvey, E Chaslus-Dancla and A Cloeckaert. Variant salmonella genomic island 1 antibiotic resistance gene cluster in Salmonella enterica serovar Albany. Emerg. Infect. Dis. 2003; 9, 585-91.

[19] EL Fonseca, OL Mykytczuk, MD Asensi, EM Reis, LR Ferraz, FL Paula, LK Ng and DP Rodrigues. Clonality and antimicrobial resistance gene profiles of multidrug-resistant Salmonella enterica serovar infantis isolates from four public hospitals in Rio de Janeiro, Brazil. J. Clin. Microbiol. 2006; 44, 2767-72.

[20] R Gupta, R Gaind, J Wain, M Deb, LC Singh and SF Basir. Characterization of non-classical quinolone resistance in Salmonella enterica serovar typhi: Report of a novel mutation in gyrB gene and diagnostic challenges. Biomol. Detect. Quantif. 2014; 2, 30-34.

[21] J Hur, YY Choi, JH Park, BW Jeon, HS Lee, AR Kim and JH Lee. Antimicrobial resistance, virulence-associated genes, and pulsed-field gel electrophoresis profiles of Salmonella enterica subsp. enterica serovar typhimurium isolated from piglets with diarrhea in Korea. Can. J. Vet. Res. 2011; 75, 49-56.

[22] M Lin, X Wu, Q Yan, Y Ma, L Huang, Y Qin and X Xu. Incidence of antimicrobial-resistance genes and integrons in antibiotic-resistant bacteria isolated from eels and aquaculture ponds. Dis. Aquat. Organ. 2016; 120, 115-23.

[23] M Gopal, S Elumalai, S Arumugam, V Durairajpandian, MA Kannan, E Selvam and S Seetharaman. GyrA ser83 and ParC trp106 mutations in Salmonella enterica serovar typhi isolated from typhoid fever patients in Tertiary Care Hospital. J. Clin. Diagn. Res. 2016; 10, DC14-DC18.

[24] H Vigre, K Barfoed, AN Swart, RR Simons, AA Hill, EL Snary and T Hald. Characterization of the human risk of salmonellosis related to consumption of pork products in different E.U. countries based on a QMRA. Risk Anal. 2016; 36, 531-45.

[25] N Nuanmuang and A Kummasook. Prevalence and antimicrobial resistance of Salmonella in minced pork from retail shops around the University of Phayao, Thailand. Naresuan Univ. J. Sci. Technol. 2018; 26, 9-16.

[26] N Bernbom, YY Ng, C Paludan-Muller and L Gram. Survival and growth of Salmonella and Vibrio in som-fak, a Thai low-salt garlic containing fermented fish product. Int. J. Food Microbiol. 2009; 134, 223-9.

[27] M Mataragas, A Bellio, F Rovetto, S Astegiano, L Decastelli and L Cocolin. Risk-based control of food-borne pathogens Listeria monocytogenes and Salmonella enterica in the Italian fermented sausages Cacciatore and Felino. Meat Sci. 2015; 103, 39-45.

[28] T Birk, S Henriksen, K Muller, TB Hansen and S Aabo. Growth potential of exponential- and stationary-phase Salmonella typhimurium during sausage fermentation. Meat Sci. 2016; 121, 342-9.

[29] W Noonpakdee, C Santivarangkna, P Jumriangrit, K Sonomoto and S Panyim. Isolation of nisinproducing Lactococcus lactis WNC 20 strain from nham, a traditional Thai fermented sausage. Int. J. Food Microbiol. 2003; 81, 137-45.

[30] A Sanguankiat, R Pinthong, P Padungtod, MP Baumann, KH Zessin, L Srikitjakarn and R Fries. A cross-sectional study of Salmonella in pork products in Chiang Mai, Thailand. Foodborne Pathog. Dis. 2010; 7, 873-8.

[31] N Sinwat, S Angkittitrakul, KF Coulson, FM Pilapil, D Meunsene and R Chuanchuen. High prevalence and molecular characteristics of multidrug-resistant Salmonella in pigs, pork and humans in Thailand and Laos provinces. J. Med. Microbiol. 2016; 65, 1182-93.

[32] SK Lim, HS Lee, HM Nam, SC Jung, HB Koh and IS Roh. Antimicrobial resistance and phage types of 1 Salmonella isolates from healthy and diarrheic pigs in Korea. Foodborne Pathog. Dis. 2009; 6, 981-7.

[33] TH Thai, T Hirai, NT Lan and R Yamaguchi. Antibiotic resistance profiles of Salmonella serovars isolated from retail pork and chicken meat in North Vietnam. Int. J. Food Microbiol. 2012; 156, 147-51.

[34] S Dorn-In, R Fries, P Padungtod, MN Kyule, MP Baumann, L Srikitjakarn, W Chantong, A Sanguangiat and KH Zessin. A cross-sectional study of Salmonella in pre-slaughter pigs in a production compartment of northern Thailand. Prev. Vet. Med. 2009; 88, 15-23.

[35] C Makendi, AJ Page, BW Wren, T Le Thi Phuong, S Clare, C Hale, D Goulding, EJ Klemm, D Pickard, C Okoro, M Hunt, CN Thompson, N Phu Huong Lan, N Tran Do Hoang, GE Thwaites, S Le Hello, A Brisabois, FX Weill, S Baker and G Dougan. A phylogenetic and phenotypic analysis of Salmonella enterica serovar weltevreden, an emerging agent of diarrheal disease in tropical regions. PLoS. Negl. Trop. Dis. 2016; 10, e0004446.

[36] R An, S Alshalchi, P Breimhurst, J Munoz-Aguayo, C Flores-Figueroa and S Vidovic. Strong influence of livestock environments on the emergence and dissemination of distinct multidrug- 
resistant phenotypes among the population of non-typhoidal Salmonella. PloS. one. 2017; 12, e0179005.

[37] L Bai, J Zhao, X Gan, J Wang, X Zhang, S Cui, S Xia, Y Hu, S Yan, J Wang, F Li, S Fanning and J $\mathrm{Xu}$. Emergence and diversity of Salmonella enterica serovar Indiana isolates with concurrent resistance to ciprofloxacin and cefotaxime from patients and food-producing animals in China. Antimicrob. Agents Chemother. 2016; 60, 3365-71.

[38] T Lima, S Domingues and GJ Da Silva. Plasmid-mediated colistin resistance in Salmonella enterica: A review. Microorganisms. 2019; 7, 55.

[39] I Kempf, E Jouy and C Chauvin. Colistin use and colistin resistance in bacteria from animals. Int. J. Antimicrob. Agents. 2016; 48, 598-606. 